(C) 1982. The Genetical Society of Great Britain

\title{
MAPPING OF AN ALCOHOL DEHYDROGENASE (Adh-A1) STRUCTURAL GENE ON CHROMOSOME 4A OF DURUM WHEAT
}

\author{
K. N. SUSEelaN, M. V. PRABHAKARA RAO, C. R. BHATIA and \\ I. NARAYANA RAO \\ Biology and Agriculture Division, Bhabha Atomic Research Centre, Trombay. \\ Bombay-400085, India
}

Received 1.vi.82.

\section{INTRODUCTION}

THE utility of isozymes as chromosome markers in polyploid wheats is well established. Many of the enzyme structural genes are present as triplicate and duplicate series in hexaploid and tetraploid wheats, respectively. Enzyme variants, except null mutations, can be identified in the heterozygous condition because they are normally codominant. Over 75 genes coding for the various isozymes have been located on different chromosomes (arms) of hexaploid wheat, largely on the basis of aneuploid analysis (Hart, 1979 and references therein). Using allelic variants, genes coding for alpha amylase have been mapped on chromosome 6B (Amy-6B1 and $A m y-6 B 2)$ and 6D (Amy-6D1) (Nishikawa et al., 1981). Hart et al. (1976) used alien translocations to map Got-D3 (now designated Got-Ag3, McIntosh, 1978). One of the reasons for the paucity of linkage data is the lack of reports on allelic isozyme (allozyme) variants. Using a variant of ADH reported earlier (Mahajan, 1975), we have mapped the Adh-A1 gene on chromosomal arm 4Ap of durum wheat.

NAD-dependent ADH (EC1.1.1.1) observed in wheat seed extracts is a dimeric enzyme, the structural gene(s) for which were located on the " $p$ " arms of the group 4 chromosomes (Hart, 1970, 1979). It was expected that the chromosomal location of the two genes coding for $\mathrm{ADH}$ in durum wheat would be on $4 \mathrm{Ap}$ and $4 \mathrm{Bp}$.

The gene for semi-dwarf plant type (Gai $1 / R h t 1)$ is located 15 crossover units from the centromere on the "p" arm of chromosome 4A in bread wheat (McVitte et al., 1978). It was therefore reasonable to infer that a dwarf durum cultivar homozygous for the Norin-10 dwarfing gene would carry Gai $1 / R h t 1$ on chromosomal arm $4 \mathrm{Ap}$. The ADH phenotype of this cultivar was ascertained and it was shown to have the common Adh-A1a allele.

\section{MATERIALS AND METHODS}

A tall durum wheat (Triticum turgidum conv. durum (Desf.) Mac Key, cultivar Bijaga yellow (gai1/gai1 Adh-A1b/Adh-A1b) was crossed reciprocally to a semi-dwarf durum cultivar Malavika (Gai1/Gai1, AdhA1a/Adh-A1a). The $\mathrm{F}_{1}$ plants were intermediate in height and their alcohol dehydrogenase zymogram showed a five band pattern. The individual $F_{2}$ families were grown separately and scored for gibberellin $\left(\mathrm{GA}_{3}\right)$ sensitivity, plant height and seed ADH phenotypes. 
For the GA response tests, seeds of the two parents and $F_{2}$ were sown in filter paper folds (Myhill and Konzak, 1967) immersed in $10^{-4} \mathrm{M} \mathrm{GA}_{3}$ solution (Gale and Marshall, 1975). Seedling height was measured on the sixth day after sowing and the seedlings then transplanted into pots. The plant height was measured at maturity to distinguish between homozygous and heterozygous GA-insensitive plants. Extraction and electrophoretic procedures used for the determination of the $\mathrm{ADH}$ phenotypes were the same as reported previously (Mitra and Bhatia, 1971).

\section{RESULTS AND DISCUSSION}

The ADH zymogram of seed extracts of cv Malavika, Bijaga yellow and their reciprocal hybrids are shown in fig. 1. Malavika shows the normal ADH pattern consisting of three bands $A D H-1-3,1-4$ and 1-5 with relative band intensities of $1: 2: 1$. These bands are formed by the association of the $\alpha \mathrm{a}$ and $\beta \mathrm{a}$ monomers. The bands correspond to the $\alpha \mathrm{a} \alpha \mathrm{a}, \alpha \mathrm{a} \beta \mathrm{a}$, and $\beta a \beta a$ dimers, respectively. The structural genes for $\alpha \mathrm{a}$ and $\beta \mathrm{a}$ monomers are located on chromosomal arms $4 \mathrm{Ap}$ and $4 \mathrm{Bp}$, respectively. In the variant, the monomer designated $\alpha \mathrm{b}$ moves faster than $\alpha \mathrm{a}$ and consequently the mobility of the $\alpha \mathrm{b} \alpha \mathrm{b}$ and $\alpha \mathrm{b} \beta \mathrm{a}$ is altered resulting in three widely spaced bands.

The $F_{1}$ hybrids show five bands ADH-1-1 to 1-5 with the dimeric composition $\alpha \mathrm{b} \alpha \mathrm{b} ; \alpha \mathrm{b} \alpha \mathrm{a} ; \alpha \mathrm{a} \alpha \mathrm{a}+\alpha \mathrm{b} \beta \mathrm{a} ; \alpha \mathrm{a} \beta \mathrm{a}$ and $\beta \mathrm{a} \beta \mathrm{a}$, respectively. The relative intensities of the bands differ in reciprocal hybrids due to the fact that the enzyme phenotype is determined in the endosperm which is a triploid tissue.

\section{(i) Segregation for $A D H$ in semi-dwarf $F_{2}$ plants}

In the first experiment only 27 semi-dwarf $F_{2}$ plants were analysed for the ADH phenotypes, of which the numbers showing normal, heterozygous and variant phenotypes were 22,4 and 1 , respectively. If the $\mathrm{ADH}$ and Gai 1 genes were not linked one would expect a $1: 2: 1$ segregation. The data deviate from this ratio suggesting linkage. Seeds harvested from these semi-dwarf plants were checked for their GA sensitivity and plant height. All were GA insensitive and semi-dwarf. However, as these data were inadequate for the estimation of linkage, another $F_{2}$ population was analysed for the segregations of $\mathrm{ADH}, \mathrm{GA}$ sensitivity and plant height.

\section{(ii) $F_{2}$ segregation for $A D H$}

When single $F_{2}$ seeds were analysed for the $A D H$ phenotype all the four phenotypes shown in fig. 1 were observed. The two five band phenotypes were grouped together. The segregation of the three classes of the normal, heterozygous and variant phenotypes fits the monogenic ratio $1: 2: 1$ (table 1 ).

\section{(iii) $F_{2}$ segregation for gibberellin sensitivity and plant height}

The $F_{2}$ seedlings were tested for their $G A$ response which showed a 3:1 segregation for insensitive and sensitive seedlings. The insensitive 


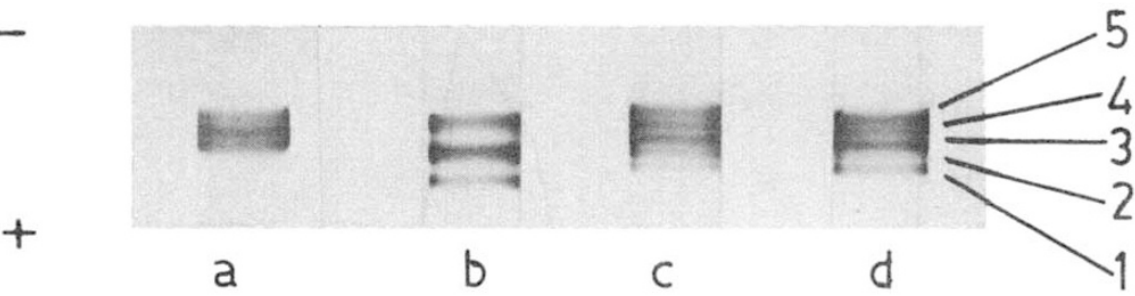

FIG. 1.-Alcohol dehydrogenase zymogram of (a) Normal (Malavika), (b) Variant (Bijaga yellow) and the $F_{1}$ hybrids, (c) Malavika $\times$ Bijaga yellow (d) Bijaga yellow $\times$ Malavika. The dimer composition of the bands in the hybrids are $1(\alpha \mathrm{b} \alpha \mathrm{b}) 2(\alpha \mathrm{b} \alpha \mathrm{a}) 3(\alpha \mathrm{a} \alpha \mathrm{a}+\alpha \mathrm{b} \beta \mathrm{a})$ $4(\alpha \mathrm{a} \beta a)$ and $5(\beta a \beta a)$.

TABLE 1

Segregation for gibberellin response, plant height and $A D H$ phenotype in the $F_{2}$ of a cross between Bijaga yellow (gai1/gai1, Adh-A1b/Adh-A1b) and Malavika (Gai1/Gai1, Adh$A 1 a /$ Adh- $A 1 a$ )

\section{Segregation for}

GA insensitive vs sensitive

Tall vs semi-dwarf

ADH (aa : ab : bb)

Single grains of $\mathrm{F}_{2}$

ADH (aa : ab:bb)

Joint segregation in the $\mathrm{F}_{2}$

Gai1/Gai1, Adh-A1a/Adh-A1a

Gai $1 /$ Gai 1, Adh-A1a/Adh-A1b

Gai1/Gai1, Adh-A1b/Adh-A1b

Gai $1 /$ gai $1, A d h-\mathrm{Ala} / A d h-\mathrm{A} 1 \mathrm{a}$

Gai1/gai 1, Adh-Ala/Adh-A1b

Gail/gai1, Adh-A1b/Adh-A1b

gai1/gai 1, Adh-A1a/Adh-A1a

gai $1 /$ gai 1, Adh-A1a/Adh-A1b

gai $1 /$ gai 1, Adh-A1b/Adh-A1b

\section{Number}

obtained

$66: 26$

$52: 21$

$25: 32: 12$

$7: 24: 12$

17

6

0

5

17

3

$53 \cdot 145$

$(1: 2: 1: 2: 4: 2: 1: 2: 1)$
Table

$(0.05)$

$3 \cdot 841$

$3 \cdot 841$

$(3: 1)$

$5 \cdot 261$

$(1: 2: 1)$

$1 \cdot 744$

$(1: 2: 1)$

$5 \cdot 991$

3

seedlings could be homozygous (Gai 1/Gai 1) or heterozygous (Gai1/gai1). These were further distinguished by measuring the plant height at maturity. However, this classification may not be totally unambiguous as can be seen from the non-discontinuity in plant height distribution (fig. 2). GA insensitive tall plants (above $75 \mathrm{~cm}$ in height) were classified as heterozygotes (Gai1/gai 1) and dwarfs as homozygous (Gai1/Gai1). The proportion of the three genotypes classified as above fits the expected $1: 2: 1$ ratio.

\section{(iv) Evidence for linkage}

Robinson (1971) has shown that the $F_{2}$ with two codominant loci is the most efficient cross for estimating linkage. The $F_{2}$ segregation for two 


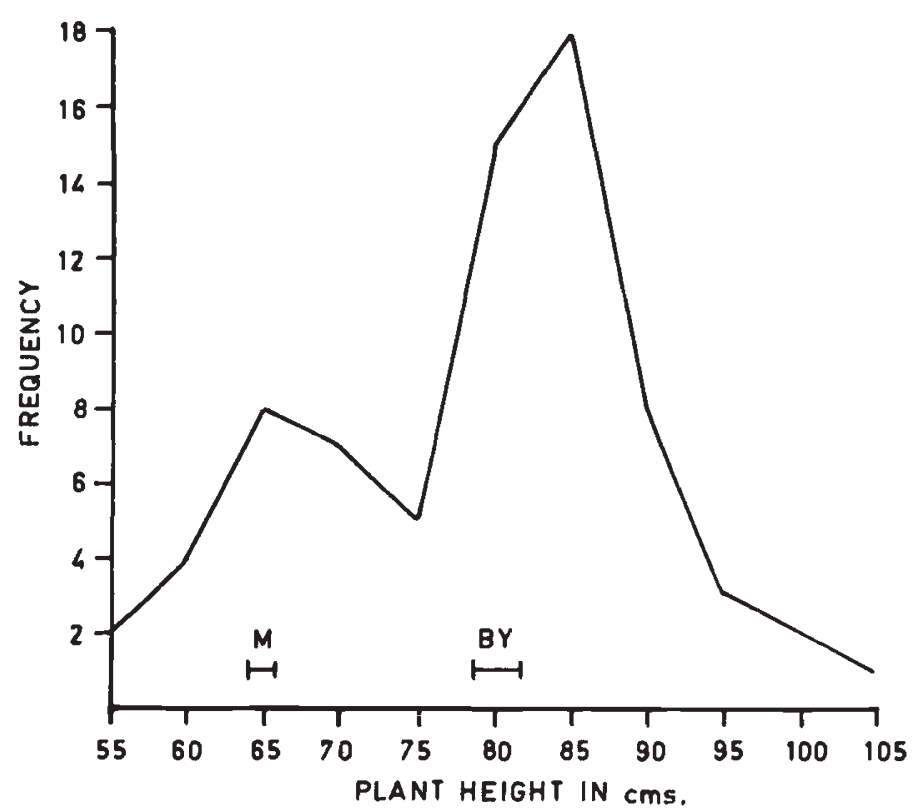

FIG. 2.-The height distribution of the $F_{2}$ plants from the cross Malavika $\times$ Bijaga yellow. The parental mean \pm SEs are given inside. M (Malavika); BY (Bijaga yellow).

co-dominant loci is expected to give a segregation ratio of $1: 2: 1: 2: 4: 2: 1: 2: 1$. The above $F_{2}$ was tested for a joint segregation of $A d h-\mathrm{A} 1$ and Gai1. The observed segregation was found to differ significantly from the expected ratio, suggesting linkage between the two genes.

\section{(v) Estimation of linkage}

The $F_{2}$ population was grouped according to the method given by Robinson (1971) for two co-dominant loci in coupling phase and a chisquare test was applied with $p=0 \cdot 5$. The value differed significantly from the expected, again suggesting linkage. The maximum likelihood estimate for $p$ was calculated by iteration and it was found that the $p$ value of $23 \cdot 1 \pm 4 \cdot 0$ gives the least chi-square value. Hence, it is inferred that the Adh-A1 locus and the Gai 1 locus are $23 \cdot 1 \pm 4 \cdot 0$ crossover units apart. It was earlier shown that the Gai $1 / R h t 1$ locus is 15 crossover units from the centromere. This allows us to infer the order of the two genes with respect to the centromere. This is shown in fig. 3 .

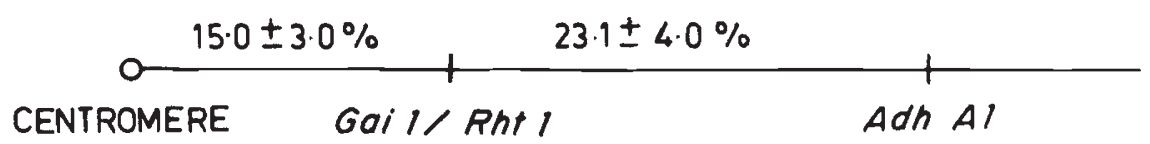

FIG. 3.-Chromosome map of the "p" arm of 4A of tetraploid wheat showing the order of the centromere, Gai1/Rht 1 locus and the Adh-A1 locus. 


\section{REFERENCES}

GALE, M. D., AND MARSHALL, G. A. 1975. The nature and genetic control of gibberellin insensitivity in dwarf wheat grain. Heredity, 35, 55-65.

HART, G. E. 1970. Evidence for triplicate genes for alcohol dehydrogenase in hexaploid wheat. Proc. Natl. Acad. Sci. U.S.A. 66, 1136-1141.

HART, G. E. 1979. Genetical and chromosomal relationships among the wheats and their relatives. Stadler Symposium. Vol. 11, University of Missouri, Columbia, 9, 9-30.

HART, G. E., McMILlIN, D. E., AND SEARS, E. R. 1976. Determination of the chromosomal location of a glutamate-oxaloacetate transaminase structural gene using TriticumAgropyron translocations. Genetics, 83, 49-61.

MAHAJAN, B. S. 1975. Isoenzyme polymorphism in the sub-tribe Triticinae. Unpublished Ph.D. thesis submitted to the University of Bombay.

McINTOSH, R. A. 1978. A catalogue of gene symbols for wheat. Proc. 5th Intern. Wheat Genetics Symposium, New Delhi, 1299-1309.

McVitTie, J. A., GAle, M. D., MARShal, G. A., AND westCotT, B. 1978. The intrachromosomal mapping of the Norin 10 and Tom Thumb dwarfing genes. Heredity 40 , 67-70.

MITRA, R., AND BHATIA, C. R. 1971. Isoenzymes and polyploidy, I. Quantitative and qualitative isoenzyme studies in the Triticinae, Genetical Research, 18, 57-69.

MYHILL, R. R., AND KONZAK, C. F. 1977. A new technique for culturing and measuring barley seedlings. Crop Sci. 7, 275.

NISHIKA WA, K., FURUTA, Y., HINA, Y., AND YAMADA, T. 1981. Genetic studies of amylase isozymes in wheat. IV. Genetic analyses in hexaploid wheat. Jap. J. Genet. 56, 385-395.

ROBINSON, R. 1971. Gene mapping in laboratory mammals. Part A. Plenum Press. London, New York, $151 \mathrm{pp}$. 